\title{
THE DECONSTRUCTION OF THICK DESCRIPTION: CHANGING PORTRAYALS OF BALI IN THE WRITING OF CLIFFORD GEERTZ*
}

\author{
Stephen L. Eyre
}

This article examines a set of writings of Clifford Geertz in an effort to elucidate the contrast between positive and interpretive science set forth by Geertz and to assess the epistemological claims for interpretive science which Geertz makes in his later work. The texts examined are: "Ethos, World View, and the Analysis of Sacred Symbols"; "Person, Time, and Conduct in Bali"; "Deep Play: Notes on the Balinese Cockfight"; "Thick Description: Toward an Interpretive Theory of Culture"; ${ }^{1}$ and Negara. ${ }^{2}$ I will first describe a method of reading termed "deconstruction" and then apply this to an analysis of the positive science/interpretive science opposition in Geertz's writing. In this analysis Geertz's attempt to repudiate a positive and adopt an interpretive stance is seen as a central problem, and I will seek to demonstrate that Geertz's shifting position on this problem results in a shifting portrayal of Balinese culture.

\section{Deconstruction as a Method of Reading}

The confounding of subject and object, and the distortion of the object by the subject, are not qualities unique to the writing of Clifford Geertz, of anthropologists, nor of social scientists in general. These are general properties of discourse. Psychoanalysts have long conceptualized such distortions, when encountered clinically, as the "transference" or "projection" of the individual's mental representations of persons--both the "self" (subject) and its objects--back onto the external world. Analytic methods have now emerged which modify these psychoanalytic concepts and incorporate related concepts drawn from phenomenology and structural linguistics in order to approach the text, instead of the individual, as a unit of analysis. I adopt the term "deconstruction" to describe the following formulation of such a method.

* I appreciate the comments of Alain J. J. Cohen, Michael E. Meeker, Herbert P. Phillips, Fitz J. P. Poole, Harold W. Scheffler, Melford E. Spiro, Peter E. Stromberg, Donald F. Tuzin, and Nathaniel Wander, which have contributed to my work on this paper. I am also indebted to the patient teaching of Paul de Man.

1. All these texts are collected in Clifford Geertz, The Interpretation of Cultures (New York: Basic Books, 1973): "Ethos, World View, and the Analysis of Sacred Symbols" [1957], pp. 126-41; "Person, Time, and Conduct in Bali" [1966], pp. 360-411; "Deep Play: Notes on the Balinese Cockfight" [1972], pp. 412-53; "Thick Description: Toward an Interpretive Theory of Culture" [1973], pp. 3-30.

2. Clifford Geertz, Negara: The Theatre State in Nineteenth-Century Bali (Princeton, N.J.: Princeton University Press, 1980).

3. J. D. Derrida, Of Grammatology, translated by G. C. Spivak (Baltimore and London: Johns Hopkins University Press, 1974). 
By "deconstructing" ethnography and theoretical writing in anthropology, it may be possible to approach an understanding of the relation of the identity of the anthropologist as subject to his portrayal of culture as an object.

I have chosen to analyze Clifford Geertz's writing for two principal reasons. First, Geertz in his work is himself sensitive to the epistemological issues posed by a "deconstructive" analysis. Since Geertz's writing is theoretically informed in this way, it is possible at many points to analyze his work in terms of its own presuppositions. This requires less inference and does less violence to Geertz's intentions than would the application of this method to a more epistemologically naive set of texts. The second reason for choosing Geertz is that his repeated self-questioning provides useful information concerning the nature of his own ethnographic and theoretical constructions. One might say that "thick" descriptions are particularly well suited for deconstruction, opening them to a critical "inspection" which Geertz himself advocates. 4

Although the following analysis is not mechanically enacted, it does operate with certain procedures which may be set forth as stages of a method. First, using structural techniques, sets of figurative oppositions (e.g.--light and dark, high and low, science and art) which recur throughout a text are identified, with particular attention being paid to oppositions which the text dwells upon and reiterates. Following this, the text is discussed as if it were an attempt to state the relations of these pairs of terms. Because these relations are generally unstable, the text's statements of these relations are often found to be contradictory. The text's progression is then seen as an effort to work through these contradictions.

To take an example, if an anthropologist were to write on the topic of "Culture and the Individual," his argument would properly begin with a definition of the two terms. Such a definition would contain a statement, perhaps implicit, of the relation of one term to the other. Subsequent elaboration of the meaning of one term would then simultaneously elaborate the meaning of the other, because of their relation. Were some contradiction to enter in (e.g.--culture is an extrinsic system and yet it exists inside the individual), this would have to be qualified and corrected, again perhaps implicitly, as the text progressed. The progression of the argument could thus be viewed in part as an attempt to stabilize the relation of "culture" and "the individual," which operate as oppositional terms in the text as it unfolds.

The proposed analytic "method" is informed importantly by the psychoanalytic principle of the internalization of relationships and their subsequent re-externalization and repetition through mechanisms of transference and projection. In the case of a text, this principle asserts an analogy between intratextual and intertextual (text/object) relations. This can be stated as follows: The relation of key oppositional terms in a text or series of texts patterns the relation between the text as a point of reference and that to which it refers outside itself. Unresolved oppositions, in other words, systematically shape and potentially distort a text's object. As a given text progresses, the relation of two oppositional terms is variously stated, with each new formulation changing the relative meaning of each term. If one of these terms refers outside the text, for example, to an object, and another term refers to the text itself, then a shift in the relations of these opposed terms (let us call them inside and outside) involves a shift in the constituted identity of the text's object. This becomes clearer if we examine, instead of a single

4. Geertz, "Thick Description." 
text, a succession of texts, and view the progression of oppositional formulations of this sort over a period of time. What we find is that, as the problematic relation of a writer to his object is variously stated, the writeris identity, as well as that of his object, changes.

The following analysis potentially brings into relief issues pertinent to both ethnographic and theoretical writing in anthropology. Geertz well articulates his identity as an anthropologist, and the relation of this identity to his object of study--culture. An attempt is made here to show that his articulation of this relation changes and, more importantly, that this changing relation changes culture itself and anthropology itself, as constituted in Geertz's writing. It may seem obvious to state that both "culture" and "anthropology" are definitional constructs and not empirical facts. What I would like to explore here are some perhaps less obvious epistemological consequences of this statement.

\section{Reading Geertz}

In what sense is the Clifford Geertz of "Ethos, World View, and the Analysis of Sacred Symbols" (1957) different from the Clifford Geertz of "Thick Description: Toward an Interpretive Theory of Culture" (1973)? To quote the later Geertz,

Studies do build on studies, not in the sense that they take up where the others leave off, but in the sense that, better informed and better conceptualized, they plunge more deeply into the same things. $s$

A study is an advance if it is more incisive-whatever that may mean--than those that preceded it; but it less stands on their shoulders than, challenged and challenging, runs by their side."

This strategy of "reading" a sequence of studies may be applied to the progression of Geertz's own thought. That is to say, Geertz's views at different points may be placed laterally and allowed to comment on one another, rather than being taken as an ordered series which moves unproblematically forward.

Geertz states in "Thick Description" that ethnographic assertion is "essentially contestable, " ? which is to say it is not grounded beyond the discourse between itself and its object. What ground ethnography finds, more central than inner consistency, is the extent to which it "takes us to the heart of that of which it is the interpretation." " Thus temporal priority can neither qualify nor reify. The ethnographic text is judged principally in terms of the cultural material it interprets. It also judges this material, however, by seeking to expose it, by "fixing it," as Geertz says, "into an inspectable form." ,

In "The Balinese Cockfight," Geertz has said that "Societies, like lives, contain their own interpretations." 10 His work contains its own interpretations

5. Ibid., p. 25.

6. Ibid.

7. Ibid., p. 29.

8. Ibid., p. 18.

9. Ibid., p. 19.

10. Geertz, "Balinese Cockfight," p. 453. 
too, as does any text. One way these interpretations emerge is simply by shifting the text's reference, by redirecting external statements back towards the text and towards the figurative oppositions inside it which ground its external statements. The proposed analytic method ultimately leads to this procedure. After identifying figurative oppositions, charting their progression, and recognizing their distortion of the text's object, the reference of the text is shifted back upon itself. Because it is assumed that the text projects its incongruities onto the world, it follows that its interpretations of that world will be, in part, displaced interpretations of itself.

In anthropology, the distinction between what is studied and the study of it is more readily asserted than maintained. For Geertz, the possibility of such a distinction is radically undermined by his insistence on the homology of culture and ethnography. What is a Balinese cockfight? Geertz tells us, "Its function, if you want to call it that, is interpretive: it is a Balinese reading of Balinese experience, a story they tell themselves about themselves." 11 But shift the reference of this statement. What is an essay by an anthropologist which he titled "Toward an Interpretive Theory of Culture"? Its function is also interpretive: it is an anthropological reading of anthropological experience, a story an anthropologist tells himself about himself.

To explore Geertz on his own terms, we must examine the relationship which exists between the different texts he has written. His later work both interprets and, at times, contradicts the earlier. Resolution emerges as certain features of his early ethnography are understood and spelled out in his later work. This later synthesis is forced, however, to try to efface and repudiate other features which inform his earlier ethnography. These features are marked in the later work by polemic and strong derision. Why is this so?

One reason that works in the "interpretive sciences," including Geertz's various writings, cannot stand on each other's shoulders is that one interpretation of ten precludes another and forces data pertinent to it off the analytic stage. The second interpretation cannot build on the first, but rather must build next to the first and must challenge the first and also fortify itself against the challenge the first poses to it. As Geertz asserts, no interpretation is privileged. Actually, no interpretation is without its adversarial counterpart.

In speaking of Balinese culture, Geertz observes that Balinese symbolic structures engender opposition

because none of these modes of experience is more than a dominant tendency, a cultural emphasis, and their subdued opposites, equally well-rooted in the general conditions of human existence and not without some cultural expression of their own, coexist with them, and indeed act against them.12

This insight applies to interpretations in anthropology, and certainly to Geertz's own thought. Perhaps the greatest antipathy of this sort in Geertz's writing is that between general theories of cultural forms and the particularistic study of cultural "texts," or, put another way, between a scientific and a literary paradigm. Grossly, the former engenders "thin" description, while

11. Ibid., p. 448.

12. Geertz, "Person, Time," p. 406. 
the latter does not see the forest for the trees. On the surface, Geertz appears in his work to move from a general to a particularistic orientation, but this movement is problematic. Neither stance is really self-sufficient. Contrary to any implied progression, Geertz's early work is already based on thick description while his later work remains suspended on a general scheme, be it antischematic. What seems progression is in part just an eclipsing of one side by another.

Some revisionist psychoanalysts have speculated that the effect of making latent content manifest is to pass through that which is manifest and effectively submerge it, rendering it similarly obscure. For example, if a dream has a surface content and a hidden meaning, and attention is directed solely to the hidden meaning, then the surface content is exempted from view, and things can as readily remain concealed there. The movement from positive to interpretive science in Geertz's work has this quality--when one position rises the other becomes submerged and opaque, but never effaced and also never unproblematic, since its operations, now concealed, go unchecked. Let us examine these poles and the tension between them in the progression of Geertz's thought.

\section{The Authority of Positive Science}

Certain of having located culture in the domain of symbolic behavior, Geertz states in 1966, in "Person, Time, and Conduct in Bali,"

What is needed is some systematic, rather than merely literary or impressionistic, way to discover what is given, what the conceptual structure embodied in the symbolic forms through which persons are perceived actually is, ${ }^{13}$ [Emphasis in original.]

This systematic project to uncover a "conceptual structuren is in pursuit of a need stated earlier in "Ethos, World View, and the Analysis of Sacred Symbols" (1957), to apply to culture "concepts explicitly designed to deal with symbolic material." 14 In 1966, Geertz is searching for these concepts in a scientific paradigm. This requires both that symbolic forms be taken as data, as objects in the external world, and that they be analyzed according to a rational system.

The view that thought does not consist of mysterious processes located in what Gilbert Ryle has called a secret grotto in the head but of a traffic in significant symbols--objects in experience (rituals and tools; graven idols and water holes; gestures, markings, images, and sounds) upon which men have impressed meaning--makes the study of culture a positive science like any other. The meanings that symbols, the material vehicles of thought, embody are of ten elusive, vague, fluctuating, and convoluted, but they are, in principle, as capable of being discovered through systematic empirical investigation--especially if the people who perceive them will cooperate a little--as the atomic weight of hydrogen or the function of the adrenal glands, 15 [Emphasis added.]

13. Ibid., p. 364 .

14. Geertz, "Ethos, World View," p. 141.

15. Geertz, "Person, Time," pp. 362-63. 
Positive scientific method brings certain general assumptions to any inquiry. Three of these are critical. First, positive science assumes that the identity of objects can be stated positively as facts. Second, it assumes that the distinct properties of specific objects can be described objectively as data. Third, it assumes that the identity and character of specific data can be compared to external criteria as a point of reference. These assumptions are axioms of positive science, and they permeate the argument of "Person, Time, and Conduct in Bali."

Geertz sets out in this paper to elucidate the symbolic forms underlying the atemporal depersonalized constructs of personhood in Balinese society. His various objective data include conventions of naming, calendrical marking of time, and patterns of social interaction. These data are of interest in relation to a reality which, as a point of reference, they take exception to. As "an especially valuable starting point," Geertz appropriates such a point of reference from the work of philosopher Alfred Schutz, taking "the paramount reality" in human experience to be the "disaggregation of the blanket notion of 'fellowmen' into 'predecessors,' 'contemporaries,' 'consociates,' and 'successors."16 The salience of Geertz's data in "Person, Time, and Conduct" derives significantly from their deviation from this "paramount reality." This deviation is what makes Balinese concepts of time and person distinctive and in need of an explanation.

To take an example, Geertz repeatedly contrasts the atemporal, apersonal social universe of the Balinese with the categories of Schutz's "paramount reality":

In Bali, the stages of human life are not conceived in terms of the processes of biological aging, to which little cultural attention is given, but to those of social regenesis.17 [Emphasis added.]

-. What looks like a celebration of a temporal process is in fact a celebration of the maintenance of what, borrowing a term from physics, Gregory Bateson has aptly called a "steady state." 1. [Emphasis added.]

The Varna System orders the title system in such a way as to make it possible to view social life under the aspect of a general set of cosmological notions: notions in which the diversity of human talent and the workings of historical process are regarded as superficial phenomena when compared with the location of persons in a system of standardized status categories, as blind to individual character as they are immortal. ${ }^{19}$ [Emphasis added.]

The varna system is inverted with respect to a fixed point of reference. It treats history as "superficial" and is "blind" to individual character. Unlike the descriptions of Bali found in some of Geertz's later work, this portrayal adduces an analytic framework which is both abstract and comparative. The Balinese are defined in contrast to Schutz's categories of historical personhood.

16. Ibid., p. 365.

17. Ibid., p. 377.

18. Ibid., p. 379.

19. Ibid., p. 384. 
The illuminating paradox of Balinese formulations of personhood is that they are-in our terms anyway-depersonalizing.

In this way, the Balinese blunt, though of course they cannot efface, three of the most important sources of a sense of temporality; the apprehension of one's comrades (and thus oneself with them) as perpetually perishing; the awareness of the heaviness with which the completed lives of the dead weigh upon the uncompleted lives of the living; and the appreciation of the potential impact upon the unborn of actions just now being undertaken. ${ }^{20}$ [Emphasis added.]

The problem of the "blunting" of temporality is construed systematically and positively. "Paramount reality" stands outside the specific Balinese setting as an objective point of reference. The Balinese have not chosen one among an endless set of possible alternatives but rather have sought to deny something universal (temporality and death) in a specific way. To deny a universal is, of course, impossible. The Balinese can never efface historical personhood. The constitution of Balinese personhood as portrayed in "Person, Time, and Conduct" hinges on an attempt to negate, but also on the impossibility of negating, this universal.

As the various symbolic orders of person-definition conceal the biological, psychological, and historical foundation of that changing pattern of gifts and inclinations we call personality behind a dense screen of ready-made identities, iconic selves, so the calendar, or rather the application of the calendar, blunts the sense of dissolving days and evaporating years that those foundations and that pattern inevitably suggest by pulverizing the flow of time into disconnected, dimensionless, motionless particles. . . .

The ceremoniousness of so much of Balinese daily life, the extent (and the intensity) to which interpersonal relations are controlled by a developed system of conventions and proprieties, is thus a logical correlate of a thoroughgoing attempt to block the more creatural aspects of the human condition--individuality, spontaneity, perishability, emotionality, vulnerability-from sight. 21 [Emphasis added.]

Isolate, contrast, and explain: these are the stages of a positive science. Balinese culture, taken as an object and described according to objectively specified features, is found by Geertz to deviate from a set of universal conditions which he uses as a standard of measurement. The ethnographic stance of "Person, Time, and Conduct," investing authority in an abstract system of science, mirrors Geertz's portrayal of the Balinese as invested in an abstract system of culture. Both systems are impersonal, taking priority over subjective individual experience. The relation of Geertz and Bali is an intratextual one, both subject and object being rhetorically constituted within the text.

\section{Symbol and Counterpoint}

There are numerous changes but also many consistencies in the development of Geertz's thought. In 1973, when he writes "Thick Description," he is still

20. Ibid., p. 390.

21. Ibid., p. 399. 
concerned with symbols. His concept of culture, in his view, is a "semiotic one." 22 But Geertz no longer frames anthropology as a positive science. It has become an "interpretive" one, a type of science which cannot be understood in the sense discussed above. Culture now, for Geertz, is a web of texts--good descriptions are "thick," overlaid. Ethnography is second or third order interpretation, fiction in effect, a thought experiment. Data are neither discrete nor isolable. Furthermore, no general principles concerning culture may be set forth and tested. Such principles

are, whatever their empirical validity may or may not be, not "scientifically tested and approved" hypotheses. They are interpretations, or misinterpretations, like any others, arrived at in the same way as any others, and as inherently inconclusive as any others, and the attempt to invest them with the authority of physical experimentation is but methodological sleight of hand. ${ }^{23}$

This amounts to a renunciation of Geertz's earlier claim that thought consists of "a traffic in significant symbols--objects in experience . . capable of being discovered through systematic empirical investigation." 24 There is no longer any possibility of objective external reference, either to frame a problem concretely or to test a formulation. The axioms of positive science, which fall like dominoes since each requires the next, have been discarded.

Has Geertz solved a problem with this new perspective? Is there a forward progression from "Ethos and World View" to "Thick Description," a span of fifteen years? Actually, these questions frame the relation of Geertz's texts to one another in a manner contrary to the principles of reading which we, in accord with Geertz's suggestion, have adopted. By these principles questions of progression and problem solving are equally distorting, whether they are repudiated or confirmed. Let us try, instead of reading each on the other's shoulders, to allow these texts to run side by side. Geertz's ongoing concern with symbol and reference, discussed systematically in his early work, provides a key to understanding his own shifting viewpoint.

I have argued earlier that all texts are animated by oppositions which are formulated variously in the text's unfolding. I focused attention on oppositions which distinguish the voice of the text (the subject) from what it describes (the object), suggesting that here lies a clue to some of the text's central distortions. This problem might be formulated: "What is the relation of the inside to the outside of a text?" With respect to another relation, that of cultural forms to their articulation, Geertz has addressed this problem at considerable length. Let us examine some of his concepts in the context of culture, and then shift their reference to the question of the anthropological text's relation to its object, and the relation of Geertz's identity as anthropologist to his portrayal of the Balinese.

In 1957, in "Ethos, World View, and the Analysis of Sacred Symbols," Geertz postulated that religion is a counterpoint of ethos and world view. What is the nature of this counterpoint? It is symbolic. What does this mean? The concept of symbol is wonderfully plastic in Geertz's writing. It is a bridge between world view and ethos and has little meaning aside from this

22. Geertz, "Thick Description," p. 5.

23. Ibid., p. 23.

24. Geertz, "Person, Time," p. 362. 
position, giving it a tremendous range of signification. It can be pushed up into the metaphysic or off towards the aesthetic and not be contradicted.

What does this say about the nature of symbolic forms, a nature we shall shortly ascribe to the anthropological text? In 1966 Geertz suggested that symbols are both "models of" and "models for" the meaningful world. "They both express the world's climate and shape it." 25 For example, a world view may be a blueprint which implements a moral and aesthetic design, but it also rationalizes an existing ethos. World view and ethos both mimic and construct one another.

This, however, poses a problem for Geertz as an anthropologist who wishes to fix upon his object of study. As we have seen, he would have all his symbols be "objects in experience." 26 The problem is that meaning is not inherent in these objects themselves, nor behavior itself, but rather it is through objects and behavior that "cultural forms find articulation." 27 Always, wherever the analytic eye turns, the ground of meaning--symbol, cultural form, or whatever-is somewhere else.

Geertz has confronted this problem clearly from the beginning, with his analogy of counterpoint in "Ethos and World View." Two melodies, he tells us, combine in a "contrapuntal view of the universe." 2 . The counterpoint hinges on the melodies being different, and yet both are melodies-the same. In this sense the counterpoint is in fact a dialectic, which progresses first towards unity and then collapses into contradiction at a higher level. The dialectic is both the unity and the contradiction.

Anthropological texts possess this contrapuntal quality. They straddle an alien reality, which they would objectively depict, and their own meaningful assumptions, which prefigure any such depiction. Anthropological texts are elusive in their grounding. Like counterpoint, they are a relation between points, subject and object, ethnographic writing and culture. Each point is known by its relation to the other. Each constitutes the other and each is constituted by the other. cally:

Later, in "Balinese Cockfight," Geertz approaches this problem more techni-

Any expressive form works (when it works) by disarranging semantic contexts in such a way that properties conventionally ascribed to certain things are unconventionally ascribed to others, which are then seen actually to possess them. 29

This formulation restates the problem of ethos and world view, and of counterpoint. Again, we encounter the juxtaposition of things which are both different and the same. A novel term takes the place of a familiar term, substituting for it. The familiar term is "conventional," contextually embedded. The novel term is of the same semantic category, but possesses its own distinct

25. Clifford Geertz, "Religion as a Cultural System" [1966], in Interpretation of Cultures (pp. 87-125) at p. 95.

26. Geertz, "Person, Time," p. 362.

27. Geertz, "Thick Description," p. 17.

28. "Ethos, World View," p. 129.

29. Geertz, "Balinese Cockfight," p. 447. 
"properties." When it is substituted, it transfers these properties into the context in which it has been substituted. This is the structure of metaphor. The particular properties of the substituting term are assigned to whatever it has taken the place of, producing an effect which is "unconventional." Geertz's more precise definition of the mediating symbol (the "expressive form") in this passage provides a significant clue for our understanding of his thought.

Let us consider again the notion that ethnography and theoretical writing in anthropology operate as expressive forms of the sort described by Geertz. As the subject, the anthropologist, seeks to describe or express the object, let us say culture, he must translate ethnographic experience into his own conceptual language. This involves ascribing "properties" familiar to the subject (the anthropologist) to an unfamiliar object (culture), with an "unconventional" result. It follows that we must focus attention on the subject or be unable to decipher his description of the object. With this intent, let us resume our examination of the changing subject--Geertz's own changing awareness--in his work. And let us frame this awareness relationally, taking Geertz himself as a text and thus, by his terms, a symbolic form, mediating between two points, crudely, let us say, between anthropology and culture taken as an object. The text of Geertz articulates the relation of these two hypothetical points.

\section{The Voice of the Ethnographer}

In an effort to fix culture as an object, Geertz first endows it with the "unconventional properties" of substance, structure, and comparability to external norms. These three attributions characterize the positive scientific framing of Balinese society which Geertz effects in "Person, Time, and Conduct in Bali." This framing is a model of, and a model for, culture. In other words, it not only describes culture, it also shapes it. Through this frame, the Balinese become contemporized, depersonalized, stylized actors of a world view and embodiments of an ethos which sustains their culture contrary to the reality of personhood set forth by Schutz. What is striking is the parallel diminution of both the Balinese persona and Geertz the anthropologist, who is also absent from the ethnographic account. This essay and this phase of Geertz's thought marks the low ebb both of the presence of the anthropologist as individual and of the presence of the individual himself in culture. This is because, as I have argued initially and as Geertz's own paradigm suggests, the two resonate, being fixed in a relation by the text.

Contrast "Person, Time, and Conduct" with "Balinese Cockfight," written six years later.

Early in April of 1958, my wife and I arrived, malarial and diffident,

in a Balinese village we intended, as anthropologists, to study. 30

Rather than the abstract voice of anthropological science, we have malarial Clifford Geertz and wife, in Bali at a certain time, planning to study a village as anthropologists. This shift of voice is remarkable, and reflects remarkably on Geertz's portrayal of the Balinese. After witnessing elaborate efforts at dismantling status in "Person, Time, and Conduct," effected by a serialized abstraction of status titles, varna hierarchy, and public titles to create an image of faceless conventionality, here we find the Balinese status-obsessed,

30. Ibid., p. 412. 
belligerent, wild, and vividly portrayed. Take Geertz's description of his experience of the cockfight:

In the midst of the third match, with hundreds of people, including, still transparent, myself and my wife, fused into a single body around the ring, a superorganism in the literal sense, a truck full of policemen armed with machine guns roared up. Amid great screeching cries of "pulisi! pulisi!" from the crowd, the policemen jumped out, and, springing into the center of the ring, began to swing their guns around like gangsters in a motion picture, though not going so far as actually to fire them. The superorganism came instantly apart as its components scattered in all directions. People raced down the road, disappeared headfirst over walls, scrambled under platforms, folded themselves behind wicker screens, scuttled up coconut trees. Cocks armed with steel spurs sharp enough to cut off a finger or run a hole through a foot were running wildly around. Everything was dust and panic.

On the established anthropological principle, "When in Rome," my wife and I decided, only slightly less instantaneously than everyone else, that the thing to do was run too. ${ }^{31}$

This is quite a different kind of writing from that of "Person, Time, and Conduct." The description is neither abstract nor comparative. The reference point for describing the Balinese is now inside the text. It is the subject--the ethnographer, and his experience. In this passage, the Balinese "superorganism" breaks apart, instantly exposing parts which "jump," "spring," "fire," "race," and "scuttle" away. Policemen armed with machine guns spring into the center of the ring, taking the place of the cocks armed with sharp steel spurs as agents of potential violence. Geertz suddenly finds himself a potential victim. And here, he encounters an interesting surprise. Geertz and his wife take shelter in a stranger's yard, but the police arrive shortly.

Seeing me and my wife, "White Men," there in the yard, the policeman performed a classic double take. When he found his voice again he asked, approximately, what in the devil did we think we were doing there. Our host of five minutes leaped instantly to our defense, producing an impassioned description of who and what we were, so detailed and so accurate that it was my turn, having barely communicated with a living human being save my landlord and the village chief for more than a week, to be astonished. We had a perfect right to be there, he said, looking the Javanese upstart in the eye. We were American professors; the government had cleared us; we were there to study culture; we were going to write a book to tell Americans about Bali. And we had all been there drinking tea and talking about cultural matters all afternoon and did not known anything about any cockfight. ${ }^{32}$ [Emphasis added.]

The slapstick tone of this passage partly conceals the weirdness of the ethnographer's "transparency," earlier referred to. The anonymous host jumps to Geertz's defense and astonishes him with a detailed and accurate description of his intentions, although Geertz had "barely communicated with a single human being." Here Geertz is saved from the clutches of the police by an

31. Ibid., pp. 414-15.

32. Ibid., p. 415. 
uncanny double who can provide detailed and accurate descriptions of things of which he had only indirect knowledge. Is this not precisely the ethnographer's role? In "Balinese Cockfight," the ethnographer's identity is highly visible, his experience mediating the description, and it also refracts through the social universe he describes. In contrast to "Person, Time, and Conduct," the intratextual relations of subject and object are no longer anchored to an external referent, resulting in a collapsing of analytic distance and a striking shift in the nature of the homology between subject (ethnographer) and object (culture). We have already examined a different form of this homology in "Person, Time, and Conduct."

The portrayal of Balinese culture itself undergoes a dramatic transformation from "Person, Time, and Conduct" to "Balinese Cockfight." The Balinese have shifted from depersonalization to a celebration of the person, reflected in the cockfight. The cockfight is a contest: persons display themselves as owners and betters, to win or lose. In "Balinese Cockfight," we see men grooming and feeding their cocks, trying one out against another, indeed in some cases spending most of their lives with them--"cock crazy," as Geertz puts it. The men have a "deep psychological identification ... with their cocks." The cocks are "the narcissistic male ego writ out in Aesopian terms." 33 The depersonalized Balinese are repersonalized in this essay, replete with phallic overtones.

Why have the Balinese changed? What has actually occurred is that the Geertz/culture counterpoint has changed inside the text. The description in "Balinese Cockfight" grounds itself not in an objective but rather a subjective, experiential referent. The subject supplants the external point of reference, which was fixed and at a distance. This is the shift from positive to "interpretive" science. Gained is the aura of immediacy so striking in this essay, and also a reciprocal emergence of the person, both in the voice of the text (the ethnographer recounts his experience) and in the object world (vivid portrayal of the Balinese individual). Because the subject/object counterpoint has changed inside the text, Balinese culture itself changes, as the text's reference prefigures it.

Mimetic Kingship: The Interpretive Stance

By the time of "Thick Description" in 1973, positive science and the external referent have become anathema. Geertz states:

The models that anthropologists have themselves worked out to justify their moving from local truths to general visions have been, in fact, as responsible for undermining the effect as anything their critics--sociologists obsessed with sample sizes, psychologists with measures, or economists with aggregates--have been able to devise against them. ${ }^{34}$

Geertz now vehemently repudiates his former positive stance. His claim to reject positive science, however, is problematic, because the interpretive science he sets in its place is itself derived from its precursor. But the new interpretive methodology resists "inspection" in a way Geertz's former methodology did not. In denying a system, Geertz no longer makes explicit

33. Ibid., pp. 417, 419.

34. Geertz, "Thick Description," p. 21. 
the operating procedures which inform his approach. This cannot represent a final resolution of the positive/interpretive science opposition. Had the opposition collapsed, anti-science polemic would be unnecessary and Geertz's earlier attempts at systematization would not have to be so vehemently repudiated. The opposition is not easily resolved, however.

Let us consider this process once more. The working through of an active opposition in the progression of a text or series of texts involves shifting and perhaps oscillating emphases on one and then the other pole of the opposition. Opposition is intrinsically unstable; strong emphasis on either term invites intrusion of its opposite. The vehement case Geertz makes for interpretive science in "Thick Description" is precarious, and is threatened both by dissipation and active intrusion of its opposite-the systematic positive science of earlier writings. "Thick Description" must and does defend itself against this threat, as we have seen.

The need for such defense is all the most pressing in this essay in that Geertz's new interpretive stance is uncomfortably exposed. "Theoretical formulations hover so low over the interpretations they govern $n^{n s}$ that the first bit of uneven terrain threatens to overturn them. Concern with conscious fabrication, meant to check sleight of hand, ties the analytic hands as well. A model or framework is lacking, hence there is considerable pressure to frame a vision which might regain altitude. A negative injunction must therefore be invoked to keep the discourse down, and models which might move upwards "from local truths to general visions" are declared anathema.

Interpretive science continues to challenge and to be challenged by positive science in Geertz's later work. Of particular interest to our discussion is his recent study of the precolonial Balinese state, Negara. Although armed with many statements embracing and defending the manifesto of "Thick Description," much of the description in Negara is systematic and abstract--far removed from the daily lives and behavior of the Balinese. In Negara, Geertz presents Bali as an exception to, if not a case disproving, utilitarian theories of the state. Such theories familiarly posit self-aggrandizement as a universal "passion" which can be used to explain the operation of political institutions of various types and in various societies. Geertz attacks this view:

The notion that politics is an unchanging play of natural passions, which particular institutions of domination are but so many devices for exploiting, is wrong everywhere; in Bali, its absurdity is patent. The passions are as cultural as the devices; and the turn of mind--hierarchical, sensory, symbolistic, and theatrical--that informs the one informs the other. 36

Geertz again challenges the validity of an external referent posited by positive science as an explanation. Passions are not a valid external referent because they are "as cultural as the devices," "cultural" here meaning constructed. If "passions," rather than being extrinsic, are informed by the same "turn of mind" that informs the strategies of the actor, then "passions" cannot offer a valid explanation of these strategies.

Negara is full of statements which, intended to describe the negara, also describe uncannily well the instability of interpretive science. Geertz states that the Balinese king "owned the country as he ruled it--mimetically; composing

35. Ibid., p. 25.

36. Geertz, Negara, p. 124. 
and constructing the very thing he imitated." 37 As Geertz describes, the king's ownership of the realm only approximated that of the gods, just as a lord's ownership only approximated that of the king's, and a peasant's only approximated that of the lord's. The king thus occupies a place in a chain of mimetic hierarchy, paradoxically both imitating and constructing a kingdom. The structure proposed here is one of substitution (the king for the gods, the lord for the king, etc.), which is very similar to the structure of the "expressive form" described by Geertz in "Balinese Cockfight." The king is a relational term: he takes the place of gods, acquiring "unconventional properties." The king then in turn is substituted for, passing his own properties unconventionally down the substitutive chain.

When the interpretive scientist writes, he fabricates. As Geertz states in "Thick Description":

Anthropological writings are themselves interpretations, and second and third order ones to boot. . . They are, thus, fictions; fictions, in the sense that they are "something made," "something fashioned." ....3

The interpretive scientist, like the king, finds himself in the middle of a substitutive chain, where he tries to imitate an object (culture) but unavoidably also constructs it, his construction in turn is reconstructed by a subject once removed from himself (the reader). He then faces the same paradox the king faces--to obtain power is to occupy a position, which defines the king, and yet in occupying a position the king constructs that position, thus "composing and constructing the very thing he imitated." The interpretive scientist is in this sense peculiarly "Balinese." Again, we see the resonance of subject and object, Geertz and Bali. Geertz denounces positive science, which would explain idiosyncratic Balinese constructions in terms of universal passions. Yet he must wrestle with the alternative he proposes: to imitate is to construct, to describe is to fabricate. On what authority can the interpretive scientist speak?

Geertz offers a solution to this problem in Negara, but, ironically, it is one taken directly from "Person, Time, and Conduct in Bali," where Geertz first argued that the fact that thought consists of "a traffic in significant symbols-objects in experience ... [makes] the study of culture a positive science like any other." ${ }^{3}$ " In Negara, Geertz states:

Ideas are not, and have not been for some time, unobservable mental stuff. They are envehicled meanings, the vehicles being symbols (or, in some usages, signs), a symbol being anything that denotes, describes, represents, exemplifies, labels, indicates, evokes, depicts, expresses--anything that somehow or other signifies. And anything that somehow or other signifies is intersubjective, thus public, thus accessible to overt and corrigible plein air explication. Arguments, melodies, formulas, maps, and pictures are not idealities to be stared at but texts to be read; so are rituals, palaces, technologies, and social formulations. 40

37. Ibid., p. 128 .

38. Geertz, "Thick Description," p. 15.

39. Geertz, "Person, Time," p. 362.

40. Geertz, Negara, p. 135. 
Does this solve the problem of a king who owns his country "mimetically; composing and constructing the very thing he imitates"? If we accept the notion that ideas are observable stuff, and that any idea is "accessible to overt and corrigible plein air explication," the paradox does disappear, as the problem is reduced to a matter of reporting. But this is a betrayal of the interpretive manifesto, for here enters an external referent--the public plein air account, against which description can be checked. Geertz's position in Negara remains contradictory and unstable. Positive science sustains its counterpoint in Geertz's writing, simultaneously criticized and propounded, never lost.

Taken as a progression, Geertz's writing appears increasingly to deny a comparative positive stance and to oppose to it an interpretive stance which resists objectification and comparability. But this exclusion is not successfully sustained in Negara. The external referent reappears in the form of the symbol, overt and objectifiable by virtue of its intersubjectivity. In insisting that observations can be checked and corrected, Geertz reintroduces precisely the external ground which interpretive science claims to deny. The effective inseparability of the two positions in Geertz's writing raises questions as to the meaningfulness of the dichotomy. Do positive or interpretive scientists exist, in any real sense? If the distinction is ultimately problematic, it is nonetheless central to an understanding of Geertz's writing on Bali, since he casts key features of his Balinese ethnography in terms of this opposition. 